\title{
What scientific information on the seismic risk to non-structural elements do people need to know? \\ Part 2: tools for risk communication
}

\author{
Stefano Solarino ${ }^{1}$, Mónica Amaral Ferreira ${ }^{2}$, Gemma Musacchio ${ }^{3}$, \\ Rajesh Rupakhety ${ }^{4}$, Hugo O’Neill², Susanna Falsaperla ${ }^{5}$, Marta Vicente ${ }^{6}$, \\ Mário Lopes ${ }^{2}$, Carlos Sousa Oliveira ${ }^{2}$ \\ (1) Istituto Nazionale di Geofisica e Vulcanologia, ONT, Roma, Italy \\ (2) Instituto Superior Técnico, CERIS, University of Lisbon, Lisbon, Portugal \\ (3) Istituto Nazionale di Geofisica e Vulcanologia, AC, Roma, Italy \\ (4) Earthquake Engineering Research Centre, Faculty of Civil and Environmental Engineering, University of Iceland \\ (5) Istituto Nazionale di Geofisica e Vulcanologia, Catania, Italy \\ (6) Laboratório Nacional de Engenharia Civil, Lisbon, Portugal
}

Article history: received January 15, 2020; accepted July 14, 2020

\begin{abstract}
The paper describes the process of turning research on disasters' mitigation into preventative actions and, more precisely, of moving from a study on vulnerable non-structural elements to solutions, tools and guidelines that help laymen to cope with seismic risk. Such a process was undertaken within KnowRISK, a project funded under the ECHO-Directorate of the European Commission, that involved Portugal, Italy and Iceland.

Information derived from damage to non-structural elements observed in recent earthquakes in countries of the project's consortium was used to design communication tools and address multistakeholders (citizens, students and building sector). These tools are: the Practical Guide, the Students Short Guide, the KnowRISK Portfolio of Solutions, the "Move, Protect and Secure" video and derived teasers, the augmented reality apps, hands-on tools and games for students (i.e. the house model activity, the students' notebooks, board games and the shake-box). The philosophy behind these products is that risks, once detected, can be mitigated by informing people and suggesting preparedness and preventative actions that need to be perceived as achievable. The tools listed in this paper are concerned with the awareness that non-structural elements seismic performance impacts economic losses, loss of functionality, and threatens life safety. We discuss the rationale behind the selection of the information that people need to know in order to increase their capacity to take actions towards the non-structural elements' reduction of vulnerability. These tools were designed engaging selected stakeholders and addressing their needs, priorities and obstacles towards mitigation of non-structural damage.
\end{abstract}

Keywords: Seismic risk; Non-structural damage; Preventive measures; Risk reduction; Communication Awareness. 


\section{Stefano Solarino et al.}

\section{Introduction}

Earthquakes are a major threat in many European countries. Nowadays they are still a substantial cause of disasters, no matter the enforcement of building regulations. In Europe seismicity mostly occurs in Mediterranean countries, essentially at the convergent boundary between the Eurasian and African plates. In northern Europe high magnitude earthquakes take place mostly in Iceland, along the Atlantic Mid-Ocean ridge at the boundary between the North American and Eurasian plate and have a potential for heavy damage [Spence et al., 2007].

In most countries with seismic design provisions, structural performance of buildings is rather compliant with the expected shaking. Nonetheless recent earthquakes have shown that losses from seismic damage to non-structural elements (NSE) can far exceed that to structural elements [Filiatrault and Sullivan, 2014]. The loss attains 65\% to 85\% of total construction's cost of commercial buildings [Sankaranarayanan, 2007]. Damage to non-structural elements occurs at seismic intensities much lower than those for structural damage. This implies that loss of life or injury, loss of value and function of buildings, and disruption of the routine of life of its occupants can occur even after relatively small earthquakes, which are more frequent than those that challenge the structural performance of the buildings. Understanding and mitigating risks that cause Non-Structural Damage (NSD) was the overall objective of the KnowRISK (Know your city, Reduce seISmic risK through non-structural elements) European Project (www.knowriskproject.com) funded under the DG-ECHO program. One of the activities of the project was to process scientific information on seismic damage associated with NSE and turn it into strategic knowledge that could prompt preventative actions by local communities.

Data on NSD caused by recent earthquakes occurring in three pilot areas of the project, namely the city of Lisbon and Azores for Portugal, the Mt Etna for Italy and Southern part of the country for Iceland, were collected and analysed; only those that could represent most common situations were then selected. The selection had the objective to provide scientific knowledge on the potential impact of damage and to derive appropriate approach and priorities for risk communication. Such knowledge is relevant for further scientific assessments including research/design of disaster management systems at a wider scale. However, when it comes to the needs of an individual citizen attempting to mitigate seismic risk in his house and in his surroundings, the approach and the language commonly used in science can make actions feel overwhelming, prospects daunting, and information useless. Since quite a large part of risk due to seismic performance of NSE can be mitigated by citizens and homeowners, the need to translate scientific knowledge into understandable and user-friendly information becomes even more compelling.

The KnowRISK project carried out such challenging task in a systematic way, thereby providing a collection of tools that must be effective on a process that starts from providing knowledge and aims at implanting preventative actions by selected stakeholders, that in this context were mainly citizens and homeowners, but may also include businesses and other practitioners.

Several risk communication tools have been implemented to build capability of local communities to cope with seismic hazards. They are thoroughly described in several papers. In this paper we would like to share with the scientific community the approach used to achieve such a task with the ambitious goal of providing guidelines to design tools that can effectively support risk communication also in other European countries. The key issue of the paper is not the description, but rather the strategy pursued to design the tools and the challenge posed by the trade-off between the need to deliver complete information and the urge to actually convey an effective message. This paper addresses therefore the issue of the selection of the information that actually people need to know in order to take actions on their safety. This information is derived from the analysis of most common NSD in the project pilot areas presented in the first part of this study [Ferreira et al, 2020].

A compact and eye-catching message can be easier to convey and it likely captures the attention of the audience. Concerning NSD, this issue is even more compelling for people who have not yet experienced a strong earthquake and therefore are likely to underestimate the risks they live in. The need for a short and incisive message implies a careful selection of the information to be used.

The design of communication tools stands on a shared view among experts from different fields revolving around seismic risk and, more precisely, seismologists, engineers, architects, risk communication researchers, sociologists and design professionals. In order to fulfil stakeholders' needs, overcome obstacles and prompt actions, the tools' design stood on specific analysis of such interested parties and their engagement in the planning process as well as in the validation phase. 


\section{Tools for non-structural seismic risk reduction}

Scientific knowledge on non-structural risk reduction is well established and some countries, such as the U.S.A. and New Zealand, have been making huge efforts to turn it into practical guidelines. In the US the Federal Emergency Management Agency (FEMA) has developed a wide variety of publications [e.g. FEMA E-74, 2015], brochures and checklists related to earthquake preparedness and non-structural hazard mitigation; some are tailored for specific type of facilities such as schools, hospitals or single-family residences. In New Zealand the Earthquake Commission (EQC) has implemented extraordinary guides and public preparedness campaigns, such as "Fix. Fasten. Don't forget” in 2017 (https://www.eqc.govt.nz/be-prepared), to help households prevent damage and injury from earthquakes, motivating people to make necessary changes in their homes (such as securing chimneys and tall furniture). The Turkish Red Crescent Society and American Red Cross developed a non-structural risk mitigation handbook [Green et al., 2003] and more recently, in 2017 the World Bank supported the "Bhutan: Improving Resilience to Seismic Risk" project, developing the "Non-Structural (falling hazards) Mitigation manual for school", intended for school administrators and teachers. These are some examples of countries that want to provide guidance and solutions on the mitigation of non-structural elements to their communities.

Worldwide disaster risk reduction frameworks (i.e. the Senday Framework) rate communication as an added value to the effectiveness of mitigation strategies and a non-structural approach to the management of risks. In Europe in the last 10 years, financing agencies have funded several projects that had seismic risk communication as a major objective [Musacchio and Solarino, 2019]. Among these, the KnowRISK project had the aim to fill a gap in the public awareness of seismic risk due to Non-Structural Elements of buildings, crucial to raise the capacity to cope with seismic hazard. To fill this gap the KnowRISK project provides a new understanding of non-structural components at European level and its performance, by carrying out scientific literature review, evidence of non-structural damage in past earthquakes and shake table tests of non-structural elements, and working together with relevant stakeholders (citizens, students and buildings' sector). to assess their risks and plan to reduce them. The scientific information was used to build specific tools to communicate preventative actions that can mitigate seismic risk: a Practical Guide, a Students Short Guide, a Portfolio of Solutions, Videos, Augmented Reality apps, hands-on tools and games. These products are described in detail in other papers [O'Neill et al., 2018; Ferreira et al., 2018a; Ferreira et al., 2018b], however they are here briefly presented in the light of the information that need to be conveyed to the selected stakeholders. We then focus on their "mitigation goals" since the criteria to select the information to be conveyed to the public are strictly linked to them.

\subsection{Practical Guide}

Citizens are the primary victims of buildings' vulnerability but definitely those who can profit from the understanding that, to improve NSE seismic performance in their houses, there are actions that can be pursued in a "do it yourself" (DIY) framework. This was the rationale behind the KnowRISK Practical Guide [Ferreira et al., 2018a; O'Neill et al., 2018] that was designed taking into account both most common NSD [Ferreira et al, 2020] and the perspective of a selected group of citizens that experienced recent NSD in Italy, in terms of knowledge, needs, obstacles [Musacchio et al., 2018].

The Practical Guide is a folded printed leaflet (Figure 1) presenting, not just mitigating solutions for seismic vulnerability of non-structural elements, rather how to approach them. It was deemed strategic to present actions easy to be implemented while guiding citizens along a path of increasing safety. The increase in safety goes along with the need for a higher level of expertise that ranges from simple interventions that can also be carried out by householders to retrofits that absolutely require specific skills. Since the Guide is intended to meet citizens' needs, households and workplaces are the selected mitigation objectives. The Practical Guide essentially leads users to look at their places with a critical eye, suggesting practical interventions that privilege DIY solutions at no cost (e.g.: move heavy or large items to the floor or low shelves) or low-cost solutions as mirrors and pictures hanging, installing latches on kitchen cabinets, etc. Solutions suggested are those relevant for the most common NSD situations inventoried in part 1 of the paper [Ferreira et al., this issue]. The layout of the practical solutions, through symbols and drawings, fills the central focus of the leaflet. Since the Guide is designed for the general public, it balances technical terms and layman needs, and is a compact, ready to use deliverable. Implementing the solutions 


\section{Stefano Solarino et al.}

shown in the guide may reduce the potential for injury and damage inside buildings by protecting their contents. Most of the solutions suggested in the Guide have been designed in order to use tools available at local hardware stores, and were tested on the shaking table of LNEC - Laboratório Nacional de Engenharia Civil, in Lisbon (Candeias et al., 2018). Tests have been filmed and used to raise public awareness, as described in 2.4.

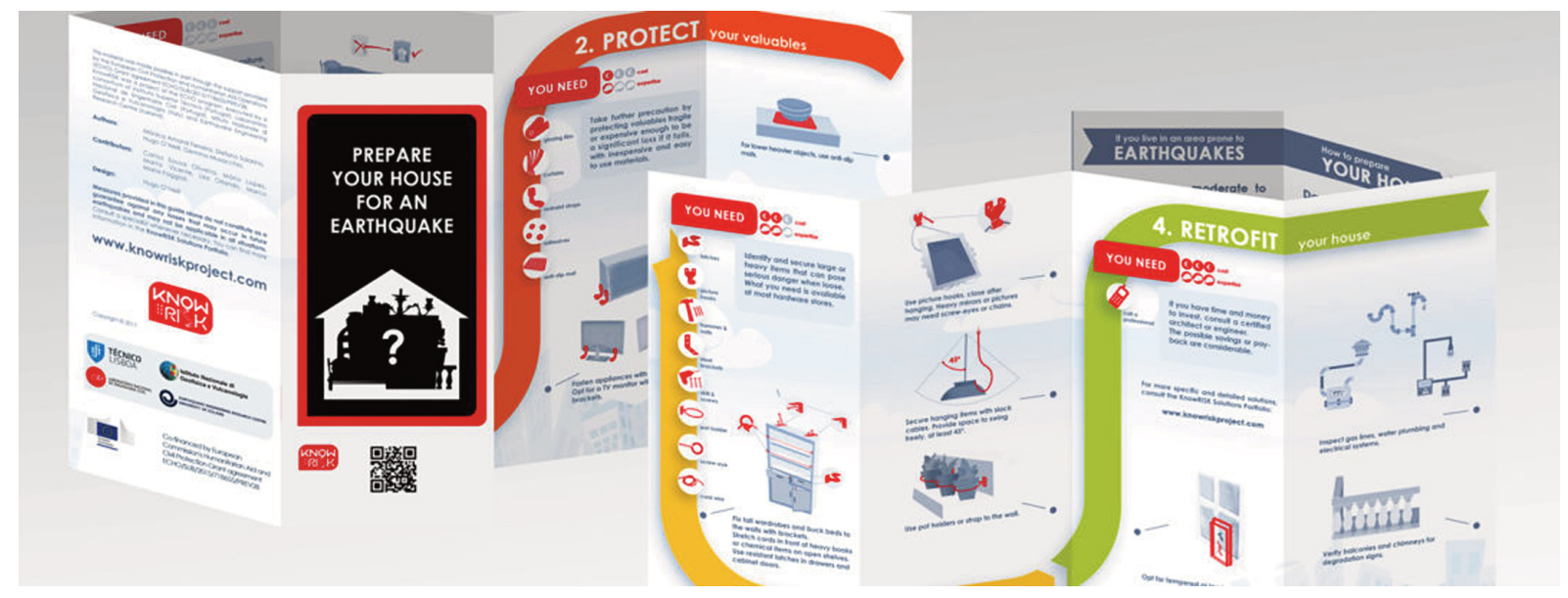

Figure 1. Polyptych of the KnowRISK Practical Guide teaches how to prepare your home, school or workplace for an earthquake.

\subsection{Students Short Guide}

Although students are not expected to take actions by themselves, they are somehow influential. They can bring the issue of how to live in a safer environment at home and at school. They are also fundamental in building resilience in a future society. However the information that students need to know is actually not centred on the "how to do", but on "what happens if you do". This is why the KnowRISK Students Short Guide (SSG) (Figure 2) is not a list of possible solutions, as for the Practical Guide, but it envisages how these solutions may be effective in making your environment safer.

In some European countries school buildings are essentially re-adapted constructions from former usage and these are often built before earthquake safety regulations. Performance of their structural elements might not be compliant with building code and they might definitely be unsafe concerning non-structural elements. The SSG meets the need to provide information that raises awareness on the issue of school buildings safety. In addition, the guide wants to drive attention to students' households. It is conceived to be a reminder for potential threats and an interactive game that can raise students' awareness of non-structural elements failures during earthquakes. It shows what happens to rooms, in a house and in a school shaken by an earthquake, with and without reducing vulnerability to building contents. The idea is that showing familiar environments and daily life situations helps students to get acquainted with the problem. At the same time highlighting the effectiveness of simple solutions builds capacity to cope with the hazards that even small earthquakes might pose.

The Student Short Guide as well as the Practical Guide are available in English, Portuguese, Italian, and Icelandic (only the PG) and can be downloaded at the KnowRISK website (www.knowriskproject.com).

\subsection{The KnowRISK Portfolio of Solutions}

There is still relatively poor compliance with code provisions that address NSE and most contents are not covered by code provisions; thus, most NSE and contents remain vulnerable to earthquake damage [Perry et al., 2012]. The KnowRISK project has engaged building sector professionals in order to understand what they need to know and how 

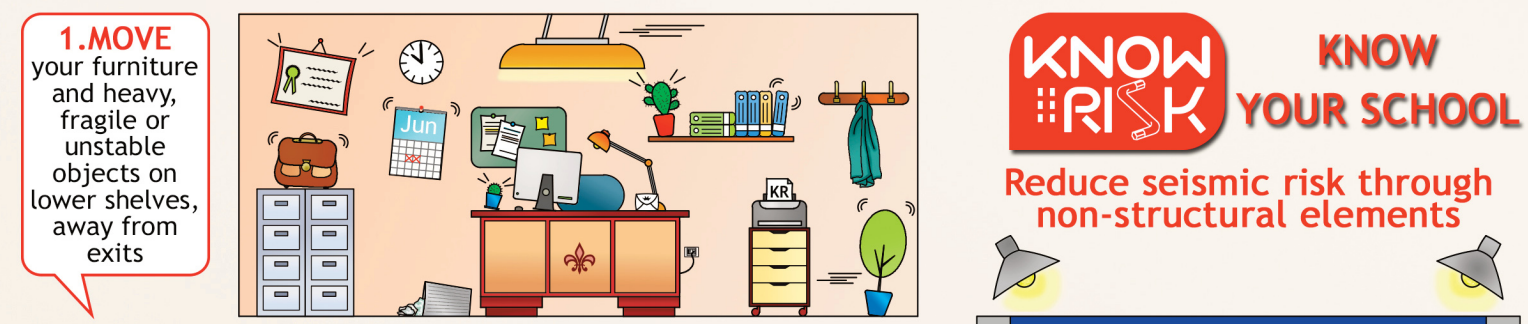

Reduce seismic risk through non-structural elements 8

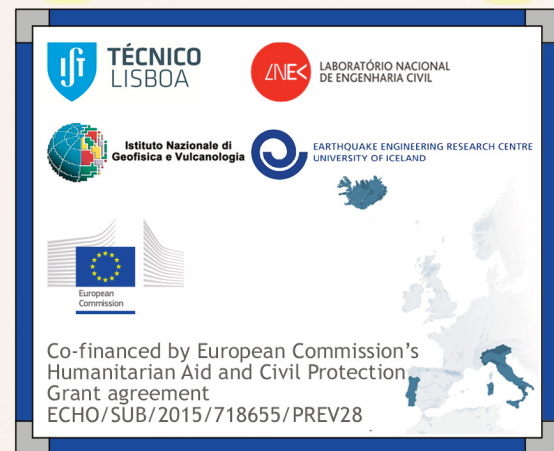

\section{SECURE tall or heavy wall-mounted, wall-mounted, suspended cabinet; hanging fans or lamps}
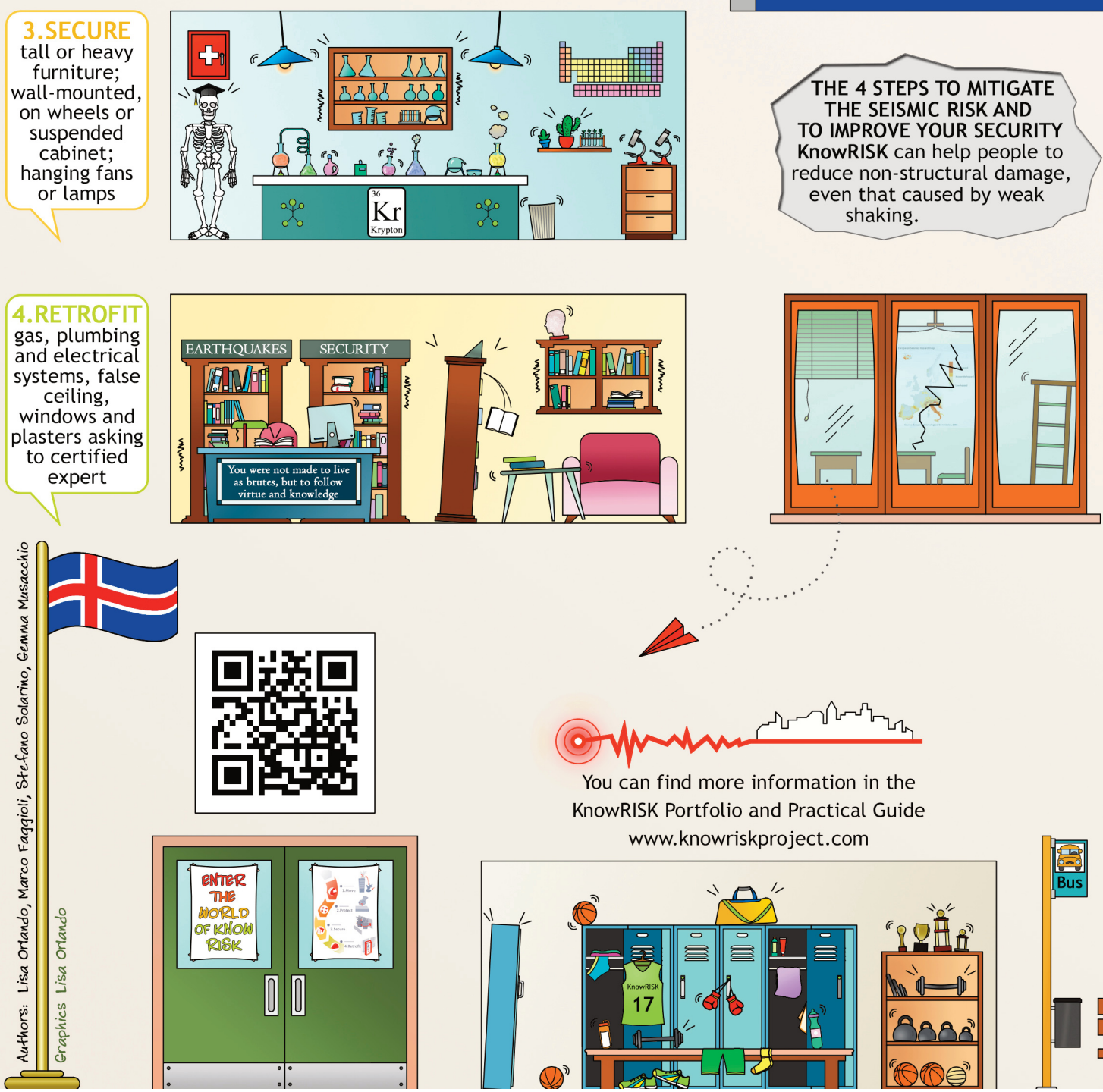

You can find more information in the KnowRISK Portfolio and Practical Guide www.knowriskproject.com

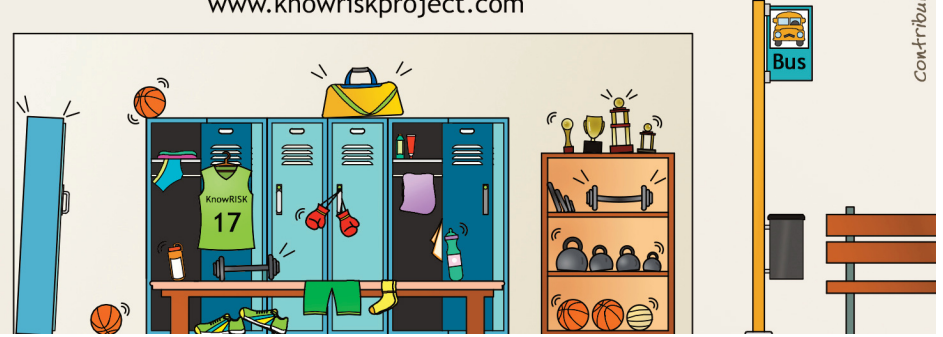

Figure 2. Student Short Guide layout. 


\section{Stefano Solarino et al.}

to help them to overcome obstacles towards actions that reduce vulnerability of those NSE most commonly damaged during earthquakes [Ferreira et al., 2020].

The KnowRISK Portfolio of Solutions (Figure 3) [Ferreira et al., 2018b] aims to alert building owners and occupants, engineers, designers, architects and other parties to the need to prevent poor performance of non-structural elements and contents in earthquakes, and provide practical solutions for that purpose in a more comprehensive manner than the Practical Guide. It is organized beginning with a brief introduction on seismic risk, major causes of damage to NSE and how damages affect the functionality of facilities, followed by preventive measures for earthquake safety divided into three main categories: i) building contents; ii) architectural: exterior and interior elements, and iii) mechanical, electrical and plumbing (MEP) elements.

The Portfolio explains and identifies potential earthquake hazards associated with non-structural elements of various types of stakeholders, namely, residential buildings, workplaces or schools, and a few common problems existing in critical structures. It describes the most common weaknesses that can result in a building being damaged by earthquakes. It enables owners to make a check-list of non-structural elements and identify their weaknesses. It also allows building systems designers, who don't have a detailed knowledge of seismic engineering, to use a range of ready-made solutions for commonly used components, adapt them to a particular project and verify the suitability of solutions by engaging a seismic specialist.

Stakeholders meant to be end users of the KnowRISK Portfolio of solutions can range from professionals to building managers. The scientific information they need to know includes a wider range of NSD [Mota de Sá, 2017] and details on solutions need to be more technical than those for the Practical Guide. All the technical solutions are the result of an extensive research and compilation of relevant safety standards performed by KnowRISK team, from multiple studies (FEMA 2005, 2015), guides, reports, case studies, periodicals, and other sources dealing with reduction of seismic risk through non-structural elements. The preventive measures for each non-structural element is presented in a separate A4 page (Figure 3) with the following structure:

i) designation of non-structural element;

ii) Table with a set of icons that provide essential information such as:

a) type of stakeholder (Homeowners or Owners and Facility Managers),

b) importance of the consequences of the potential damage expressed in terms of three types of risk:

Life Safety (LS): The risk that people will be struck by a falling object, cut or otherwise injured. Could anyone be hurt by this component in an earthquake?

Property Loss (PL): The risk of economic losses to repair or replace damaged items. Could a large property loss result?

Functional Loss (FL): The risk that an essential function will be disrupted. Could the loss of this component cause an outage or interruption?

c) skills needed to implement the proposed solution. The three different types of skills/expertise needed to implement the solution are:

Do-It-Yourself (DIY) - these are simple, generic details for non-structural items found in the home, office, classroom, or small business, that can be installed by a handyman using common tools and readily available materials.

Non-Engineered (NE)

Engineering Required (ER) - these are schematic details that need to be developed by a design professional and will require installation by a specialty contractor. The designation Engineering Required has been used for items where the self-help approach is most likely to be ineffective. Consult a structural engineer for seismic connection and separation details in a building services or mechanical engineer responsible for the design of non-structural elements.

d) Indication of the repair time of the non-structural element;

e) Indication of technical solution costs.

iii) Typical causes of damage;

iv) Recommended methods, i.e., technical solutions to reduce seismic risk. 
12. Desktop computer equipment, printers, copiers, scanner

\begin{tabular}{|l|l|l|l|}
\hline Stakeholder & Life safety & Property loss & Functional loss \\
\hline Solution/ Expertise & Repair time & Costs of strengthen \\
\hline & & 6 &
\end{tabular}

\section{Typical causes of damages}

Desktops, monitors, are tossed from desks, cracking screens and damaging hard drives.

Recommended methods

Fix monitor to the wall or to the desk.

Wall-mounted TV or video monitors typically utilize a manufactured mounting bracket. The mounting bracket must be fastened to wall stud. TV or video monitors must be secured to the bracket. It's crucial that the wall or ceiling that you are mounting your television on is appropriate - some mounts are not manufactured to be mounted onto walls or ceilings with steel studs or cinder block construction.

Locate desktop computers and printers far enough from the edges of tables and desks to prevent them from sliding and falling in an earthquake. Non-slip rubber mat can be used to prevent movement. If the TV or monitor is on a base or stand, these can be fastened using strap restraints.
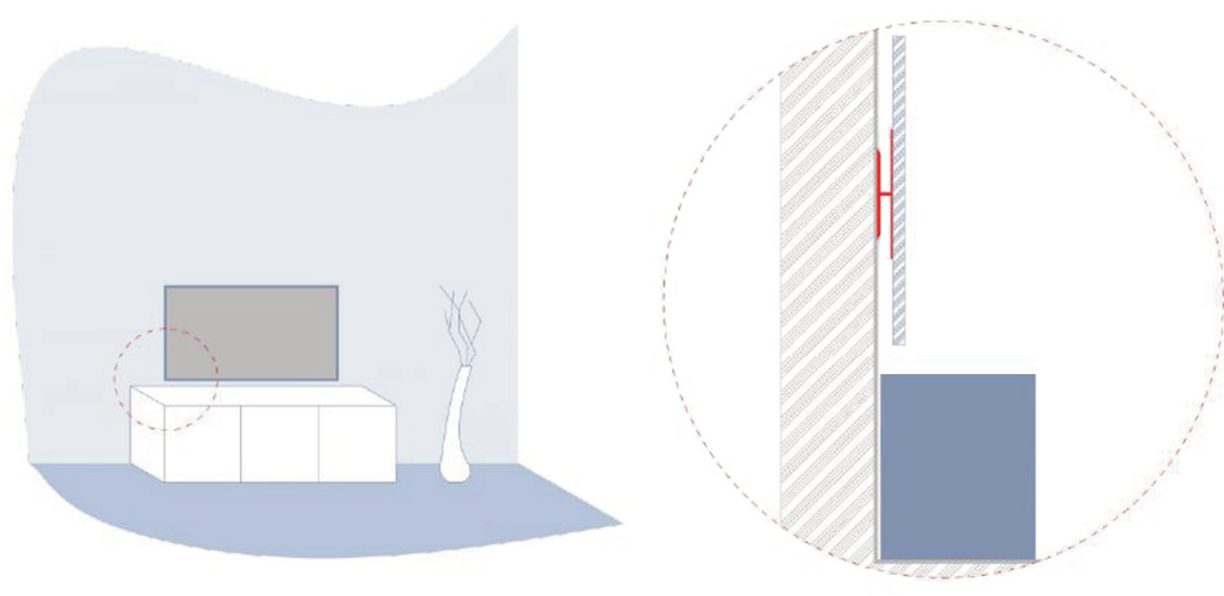

Technical drawing by $M$. Vicente

Secure electronic equipment to the floor or table surface with braces.

Figure 3. Example of recommended methods, i.e., preventive measures to reduce seismic risk (available at https://knowriskproject.com/portfolio/). 


\section{Stefano Solarino et al.}

\subsection{Move, Protect \& Secure videos awareness campaign}

In order to disseminate the message about actions the KnowRISK project implemented a video awareness campaign that stood on a main short-length film (15 min), and four teaser-spots (30-40 sec) (Figure 4). The campaign is aimed at raising awareness that by taking simple and inexpensive measures "Move, Protect \& Secure", one can reduce non-structural damages. The scientific information that people need to know is provided in the form of a motto, "Move, Protect \& Secure", that retrieves the three main steps defined in the Practical Guide, those that require the least effort and cost. The steps are a direct echo of what was captured in film during the shake tests, the comparison of consequent damages in furniture and respective contents during an earthquake, when retrofitted and non-retrofitted. One of the spots presents the full range of the three protective measures, and the other three present them in separate (Figure 4).

The videos are in Portuguese and were translated into the two official languages of the project: English and Italian. These four videos were made available on several online platforms and partner websites (schools, key government officials, business leaders and science outreach initiatives). The video campaign is available on YouTube and KnowRISK website (https://www.youtube.com/channel/UCQng71zMIJE0PeVHP9ktWIQ; https://knowriskproject.com/moveprotect-secure/).

To produce the video awareness campaign, a series of earthquake simulations were carried out on a 3D shake table at LNEC [Candeias et al., 2018] with different types of non-structural components in order to assess their seismic performance, with and without complementary restraining devices.

The simulations were performed in a full scale bedroom, mimicking the shaking of real earthquakes that occurred in Iceland from the relevant seismograms. The initiative of making a film or videos for education and communication purposes was an innovative approach of engaging with the general public. It provides appealing ways to directly see effects on vulnerable environments. Such a campaign is intended to perform as an extremely powerful tool to raise awareness and to motivate people to act.
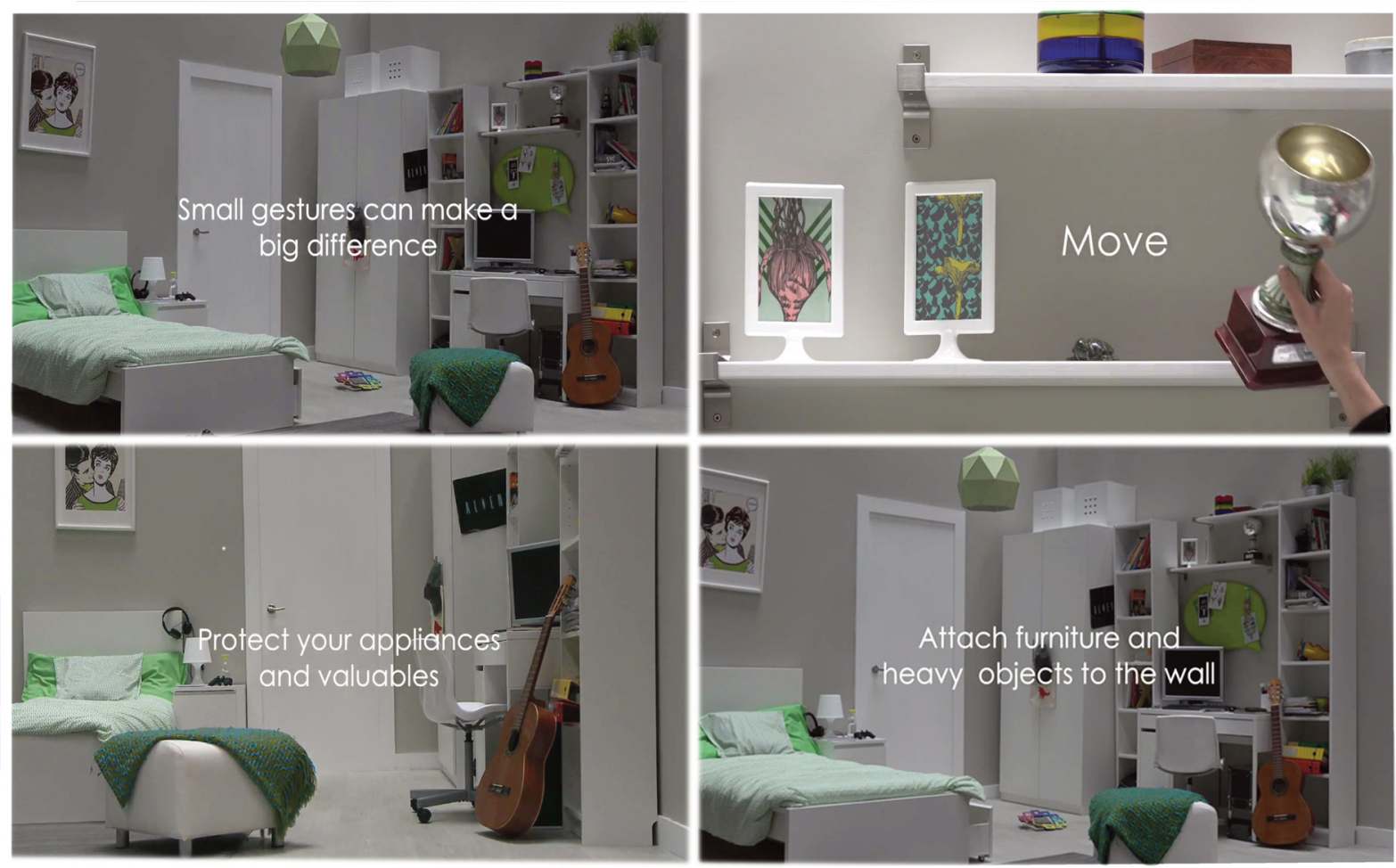

Figure 4. Campaign snapshot on YouTube. 


\subsection{Augmented reality}

A specific exhibit was created and combined with Augmented Reality applications (AR APPs) to highlight the role of non-structural elements in seismic risk. It allowed users to see animations (images and videos) of earthquake effects by pointing tablets or smartphones to specific objects, which were "animated" by the AR software. Based on web technology, our APPs exploit the Wikitude Software Development Kit (SDK) for Android. SDK “augments” the real world overlaying information on target objects (in our exhibit, photos and images of buildings and furniture typically found in a house). Reitano et al. [2018] provides an in-depth description of the exhibit and its use in dissemination events for students and laypersons, promoting their awareness of earthquake damage. The exhibit established a high interactivity with the visitors, and let them see to what extent and in which way non-structural parts of a building can be damaged even by a small magnitude earthquake (Figure 5). The scientific information provided to the visitors by AR encompassed the content of the KnowRISK Practical Guide and described the simple actions everyone can do to reduce non-structural damage in various contexts, from home to school or office.

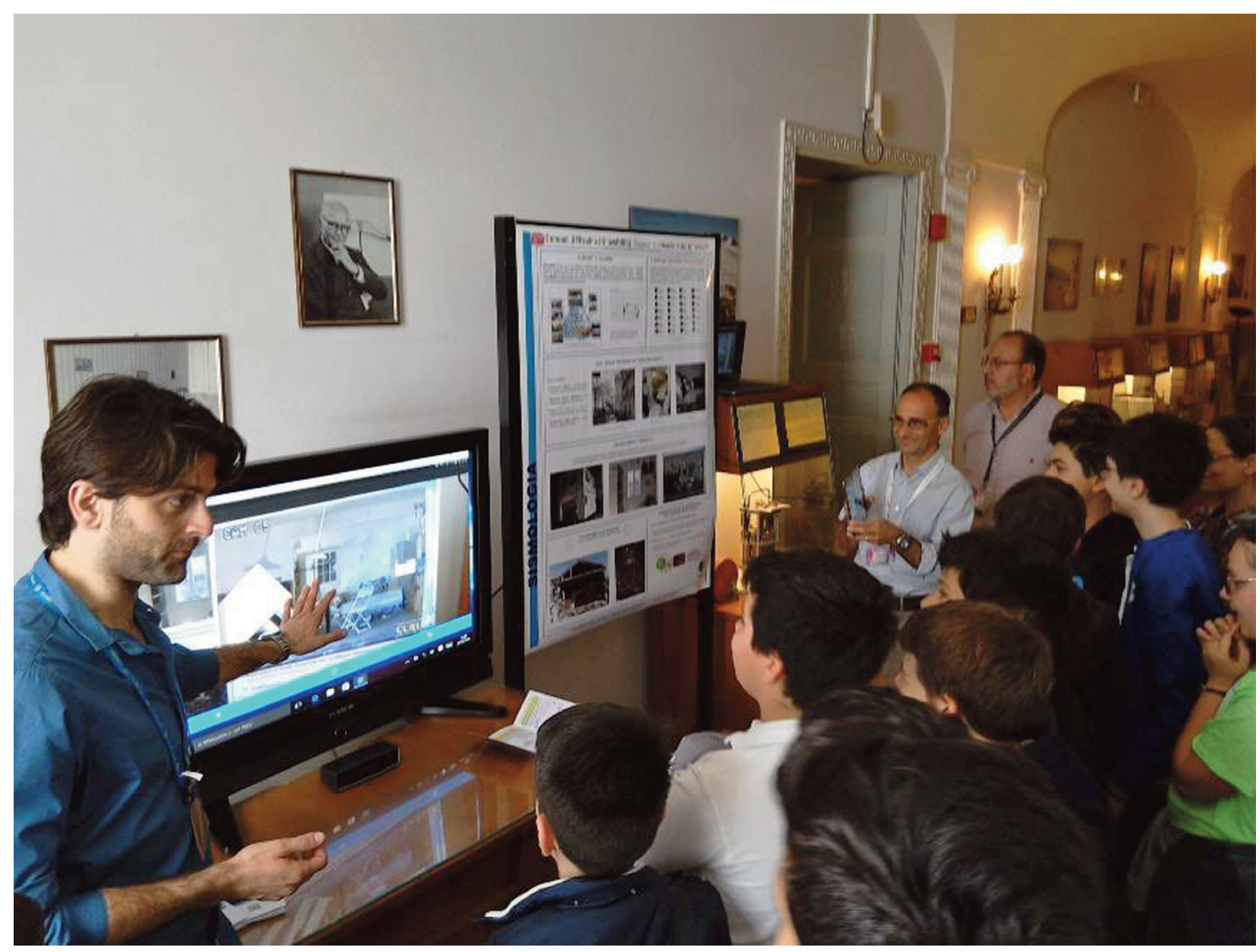

Figure 5. The prototype of the KnowRISK exhibit based on Augmented Reality, for the reduction of NSD. Photography by Susanna Falsaperla.

\subsection{Additional educational tools}

The KnowRISK project addressed students with a specifically designed risk communication campaign and implemented a protocol to be used in schools. This protocol made use of the Practical Guide, the Students Short Guide and the teaser-videos together with hands-on tools that were intended to be "second level" applications as they are designed for an already experienced audience. They are in fact sort of tests of what has been learnt in an 


\section{Stefano Solarino et al.}

education path that the KnowRISK implemented [Silva et al., 2018; Musacchio et al., 2018]: the students must apply their acquired knowledge to check their increased capacity to be prepared in case of an earthquake.

Among these additional deliverables, we quote in this paper the House Model Activity and the table game "Do it right!”.

The House Model is an educational activity in which students can test the vulnerability of a house by placing, inside a model resembling a house, furniture and ornaments and shaking it to see what consequences may derive from an incorrect layout. The scientific information that students need to know is derived from the observation of what happens to the furniture in the house models. This risk communication intervention aimed at i) fostering knowledge on seismic risk and non-structural protective measures; ii) stimulating the formation of beliefs that encourage the adaptation of protective measures; and, iii) fostering the development of protective behaviour intentions [Silva et al, 2017]. During the House Model Activity, each group of students worked on one specific room (living room, office, kitchen, bedroom), managing a set of tasks:

- Assemble a given set of furniture according to the house division;

- Display the furniture set freely inside the room;

- Assemble the several house parts together and shake the model in a way to simulate the action of an earthquake.

This shaking test and its consequences allowed students to have a vision of the effect of an earthquake inside a regular house (Figure 6a);

- With the effects of the earthquake in mind, students go back to work and are able to rearrange the furniture in a safer way. After a correct display of furniture, students were invited to simulate other protective measures such as fixing tall furniture to the walls, moving heavy objects to lower shelves, moving beds away from windows or, even, placing heavy curtains on windows to prevent broken glass from spreading through the room (Figure 6b).

After these stages students were invited to write signs to place inside their room, displaying three of the protective measures adopted. This last stage enabled students to use the house model to communicate seismic risk to others. The board game "Do it right: be safer!" is a card game where students have to decide which mitigation action belongs to the appropriate intervention. There are four mitigation steps, of increasing cost and required skill (move-protectsecure-retrofit), located on four quadrants of different colour from red to green.

Students must place each card on one of the coloured boards according to the four types of actions. For example, moving the furniture to avoid blocking the exit in case of fall belongs to the red quadrant. Fixing frames or wardrobe to the wall belongs to the yellow quadrant. Some cards display "wrong" actions in terms of vulnerability mitigation and the students must discard them justifying their choice. The game is designed for older students, from high school to university. A more detailed description of this game can be found in Solarino et al. [this issue].

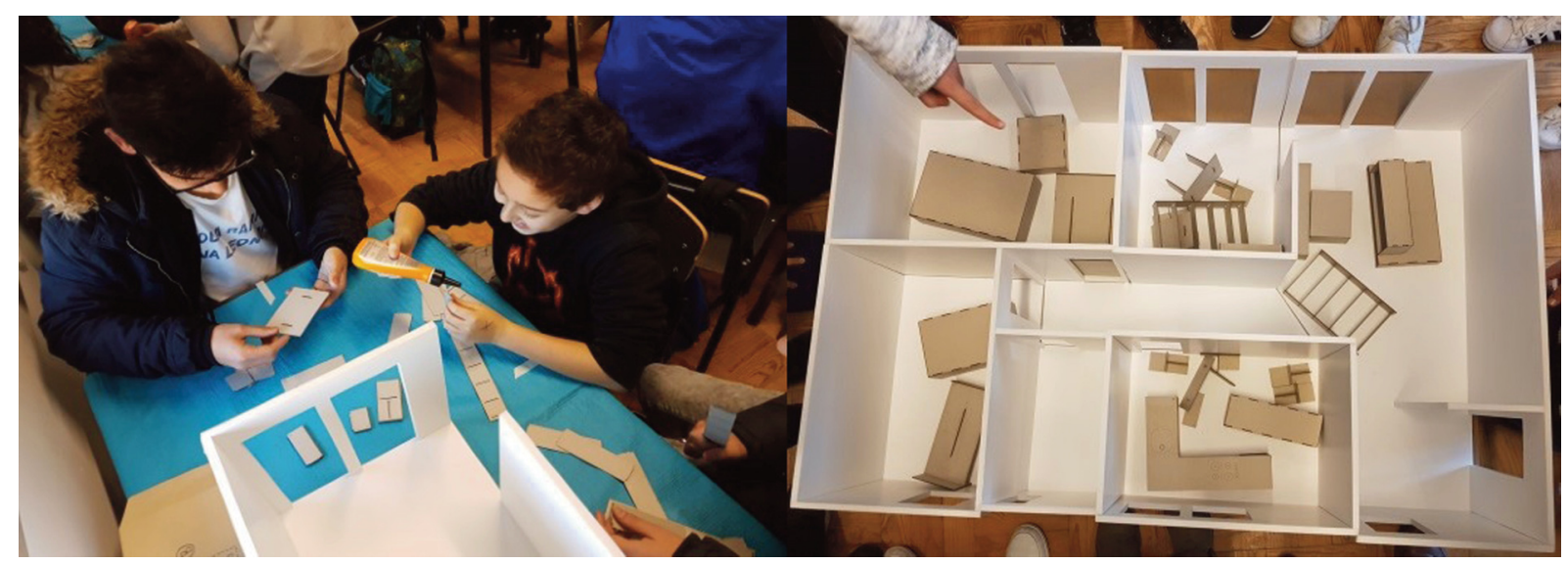

Figure 6a. House model after shake test. 


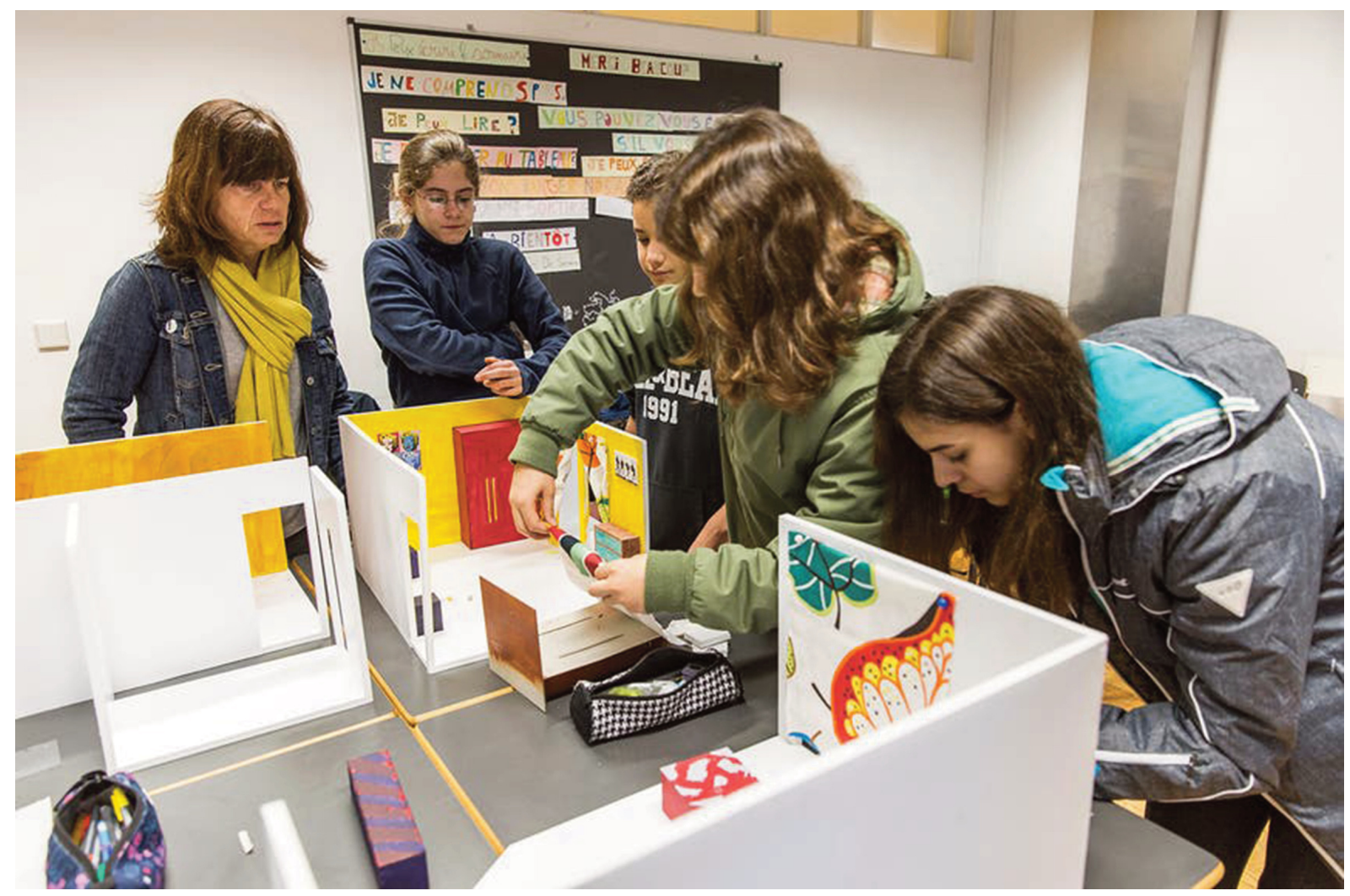

Figure 6b. Students handle the last details of their room. Photography taken by Nuno Patrício - RTP Notícias.

\section{What scientific information on non-structural elements seismic risk people need to know?}

The quantitative assessment of NSD on architectural components, utilities and building contents was based on observed damage from recent earthquakes in the project's pilot areas that is discussed in part 1 of this paper [Ferreira et. al, this issue], and was the relevant scientific reference to be addressed in tools for risk communication.

The research, as expected, provided more information than needed in a straightforward and compact tool like a printed leaflet or a short video to be used for communication purposes. A wide range of damage was detected in the three pilot areas, revealing common attributes and peculiarities due to the cultural and historical situation in each country. For example, in the Mt Etna pilot area NSD on many historical buildings was on elements typical of the local architectural style, i.e., the external ornaments of the Sicilian Baroque developed since the XVII th century and largely used in the reconstruction following the $1693 \mathrm{Val}$ di Noto earthquake. In Iceland, the modern low-story buildings are mostly building code compliant. These did not experience heavy structural damage nor suffered NSD of architectural components due to the limited number of external ornaments. They experienced instead widespread damage to building contents. These differences are crucial in the selection of what scientific information people need to know and therefore need to be addressed when designing and refining the communication tools. However, to avoid overwhelming the public with too many details, we deemed relevant scientific information that can enhance the impact of the educative tools while selecting only elements common to all countries. In such a framework information highlighting actions that people can easily take care of are relevant: this information delivers the idea that prevention can be indeed effective in raise safety.

Constraints on the selection of information for the public were the followings:

a) the analysis of needs, obstacles and priorities performed on selected stakeholders. This analysis defined what 


\section{Stefano Solarino et al.}

and how simple seismic risk mitigation solutions could be implemented by non-experts;

b) shake table tests with different types of NSE in order to assess their seismic performance, with and without preventive solutions for reduction of NSE vulnerability;

c) a list with most NSE s compiled in the international literature and an adaptation to the uses and practices in the three participant countries;

d) the feedback given by stakeholders to adjust tools to specific needs

The above constraints led to the criteria for selection of NSD to be taken into account for the KnowRISK communication tools as follows:

1) The sharing between different countries. In this perspective NSD common to all countries were considered as a priority. As already stated, the different epoch of construction, construction techniques, cultural setting, environmental parameters (latitude, temperature) and intended use of the buildings in the pilot areas proved that the largest similarities are on building contents, i.e. the majority of the information regards furniture, cabinet doors, windows, suspended ceilings. Architectural components were then deemed as a limited selection of items.

2) The economic issues and cost-benefit considerations. In this framework, a special attention has been devoted to more expensive items, that were difficult to be replaced or that may have further consequences on safety when damaged. Examples are valuable vessels or paintings, fragile artwork, gas cylinders, hazardous materials.

3) The impact on the safety of the residents, with a special attention to young children (especially in schools) and the situation where occupants are highly vulnerable (earthquakes during the night) or at least less reactive. Examples are storage racks, shelves, tall cabinets.

4) The maintainance of free escape routes. All items that, although not valuable nor harming, may make it hard to find a way out after the earthquake and, as a consequence, increase the exposure to further damage or shaking. Examples are doors, glazing and windows.

5) All items that are not included in the previous index but may preclude living in a building due to damage or malfunctioning of the infrastructure. They are the piping system, the water tanks, the chimneys, etc.

\section{Final Remarks}

We designed and implemented tools to inform about NSD and promote proactive attitudes that may enhance safety. Our selected audience was classified into three major stakeholder groups, namely citizens, students and the building sector, which were addressed with specific risk communication tools.

The idea was to promote increasing steps of stakeholders participation: awareness, interest, engagement and commitment.

The tools aimed at citizens are based on the DIY approach and the suggested actions to improve safety belong to common sense such as preventing free standing objects from moving, special locks to inhibit the opening of cabinet doors, storing of non-used items in a safe place and loose items in a secured container. In the DIY approach, engagement is triggered by the simplicity of some interventions (ie: just move the furniture to safer places), which could be undertaken without the assistance of a professional and yet provide immediate effects on safety. Nevertheless, we had to face two issues.

The first issue is that NSD is not systematically assessed in post-earthquake surveys. There are not many case studies with a wide range of data and it is therefore difficult to derive this type of scientific information that people need to know. In order to overcome such lack of information, in this work we profited from an ad-hoc study carried out within the KnowRISK project on pilot areas located in the participating countries and made a relevant list of NSDs. Since the study results included more information than necessary, a selection upon relevance was made to answer the question of what people really need to know.

The criteria applied for the selection aimed to preserve the key-issues while trying to account for the different cultural and historical background of each country. This resulted in a balance between detail and simplicity of the messages.

The second issue is that, in order to carry out effective communication stakeholders-oriented tools are of paramount importance. These need not only have an understandable language but the scientific level has to be adjusted strategically. The analysis of stakeholders' needs, obstacles and priorities, as well as feedback, are essential for 
designing and implementing effective tools. The communication tools prepared in the KnowRISK project were therefore able to convey messages to different recipients, from students to common citizens to stakeholder. In each case, the communication, being based on data extrapolated from real situations, is specific to the problem being addressed (in this case seismic risk) and its scope (mitigation).

Risk communication is a process that takes time, planning, and persistence. A big issue is to estimate its impact on the public and its efficacy.

In general, the effectiveness of a risk communication can be assessed only by looking at what happens to a community at the next earthquake.

That would obviously be the most representative case study but it would need a long time observation. However even in such an ideal case we should balance our assessments taking into account the magnitude of the event, the hypocentre location, how long before the participation to the communication campaign occurred, whether the earthquake occurred at night, during the day, during the touristic season, in winter or summer time, the social vulnerability of the area, the risk prevalence in the area, the demographic impact by past earthquakes [De Lucia M. et al., 2020] and several other issues.

Neverthless, within the KnowRISK project we specifically designed a questionnaire to quantitatively measure the change in Knowledge Attitude and Preventative actions before and after the communication campaign in schools [Platt et al, 2018]. The analysis of responses to this questionnaire shows that in general the suggested solutions to reduce vulnerability to NSD were all very well understood anda accepted (Figure 7).

We may thus assess that our approach to risk communication was effective in raising awareness and, possibly, in fostering best practices. The approach could be applied to other risks, and in other countries. We believe that the selection of information to be included in our communication campaign was one of the key strengths together with the adaptation of the language and technical content to the various stakeholders.

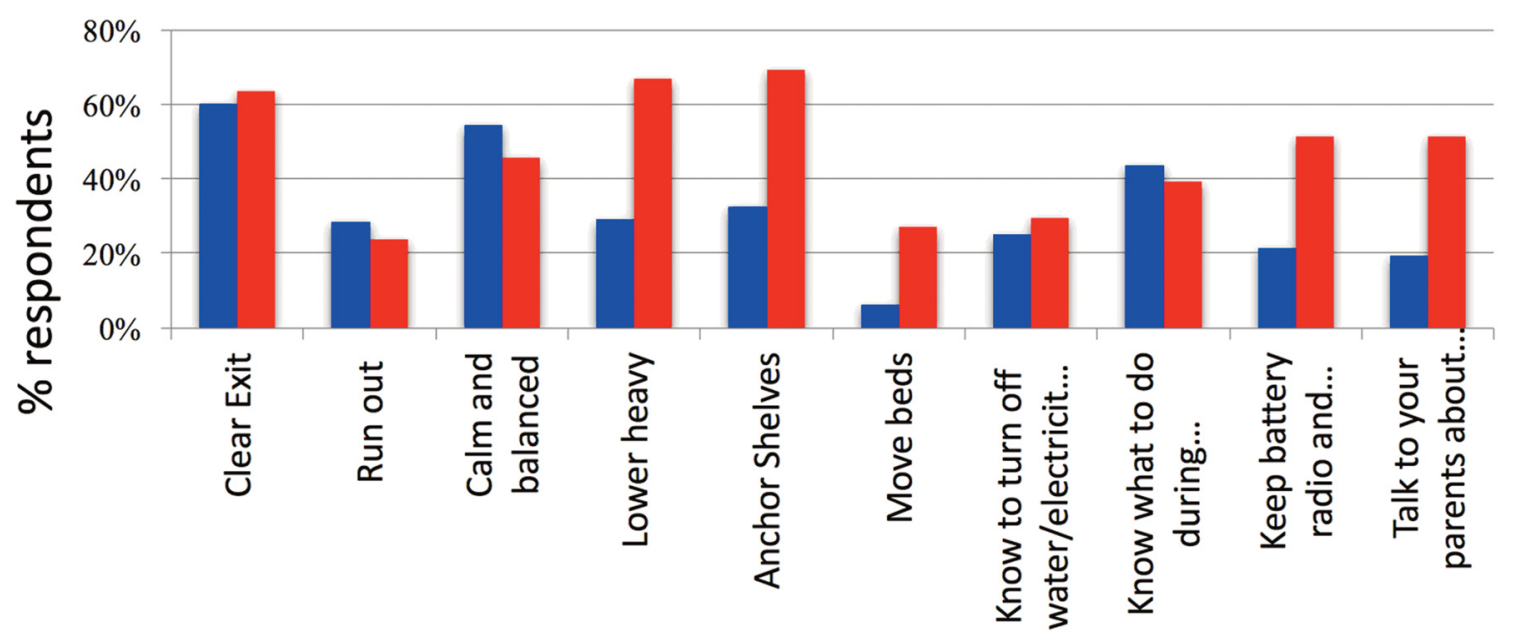

Figure 7. Preliminary results from the KnowRISK questionnaire [Platt et al, 2018] for the evaluation of changes in awareness concerning preventative actions. In blue are responses before the communication campaign in schools, and in red are responses after the campaign.

Acknowledgements. We are indebted to an anonymous reviewer whose suggestions greatly improved the paper. KnowRISK is co-financed by European Commission's Humanitarian Aid and Civil Protection Grant agreement ECHO/SUB/2015/718655/PREV28. It is a project that involved four different European research centers and universities under the coordination of the Instituto Superior Técnico (Portugal). The partners are the Istituto Nazionale di Geofisica e Vulcanologia (Italy), the Laboratório Nacional de Engenharia Civil (Portugal) and the Earthquake Engineering Research Centre (University of Iceland). We acknowledge all the participants of KnowRISK group for the fruitful discussions and support. 


\section{Stefano Solarino et al.}

\section{References}

Candeias, P., M. Vicente, R. Rupakhety, M. Lopes, M.A. Ferreira and C.S. Oliveira (2018). Seismic Performance of Non-structural Elements Assessed Through Shake Table Tests: The KnowRISK Room Set-Up. In Rupakhety R., S. Olafsson and B. Bessason (eds). Proceedings of the International Conference on Earthquake Engineering and Structural Dynamics, Geotechnical, Geological and Earthquake Engineering, Springer International Publishing AG, 47, 293-307. https://doi.org/10.1007/978-3-319-78187-7_22

De Lucia, M., F. Benassi, F. Meroni, G. Musacchio, N.A. Pino and S. Strozza (2020). Seismic disasters and the demographic perspective: 1968, Belice and 1980, Irpinia-Basilicata (southern Italy) case studies. Ann. Geophys., 63, 1, SE107, 1-26.

FEMA E-74 (2015). Reducing the Risks of Non-structural Earthquake Damage - A Practical Guide, Federal Emergency Management Agency (FEMA), Washington. https://www.fema.gov/fema-e-74-reducing-risks-nonstructuralearthquake-damage

FEMA 74-FM (2005). Earthquake hazard mitigation for non-structural elements. Field Manual. Federal Emergency Management Agency (FEMA), Washington. http://mitigation.eeri.org/files/FEMA74_FieldManual.pdf

Ferreira, M.A., S. Solarino, G. Musacchio, F. Mota de Sá, C.S. Oliveira, M. Lopes, H. O’Neill, L. Orlando and M.M. Faggioli (2018 a). KnowRISK tools for preparedness and community resilience: Practical Guide, Short Guide for Students, Portfolio and Video, Proceedings of the 16th European Conference on Earthquake Engineering, 18-21 June 2018, Thessaloniki, Greece.

Ferreira, M.A., C.S. Oliveira, F. Mota de Sá, M. Lopes and I. Pais (2018 b). KnowRISK Portfolio of solutions: for the reduction of seismic risk through non-structural elements. (available at:www.knowrisk project.com)

Ferreira, M.A., F. Meroni, R. Azzaro, G. Musacchio, R. Rupakhety, B. Bessason, M. Lopes, C.S. Oliveira and S. Solarino (2021). What scientific information on non-structural elements seismic risk people need to know? Part 1: Compiling an inventory on damage to non-structural elements. Annals of Geophysics, 64, (this issue) https://doi.org/10.4401/ag-8412

Filiatrault, A. and T. Sullivan (2014). Performance-based seismic design of non-structural building components: The next frontier of earthquake engineering, Earthquake Engineering and Engineering Vibration, 13:17-46.

Green, R., Ö. Caliskan, B. Sungay and Z. Paci (2003). Non-structural risk reduction handbook. Boğaziçi University, Disaster Preparedness Education Project, Kandilli Observatory and Earthquake Research Institute, and the Center for Disaster Management, http://www.koeri.boun.edu.tr/aheb/dpeu_english.pdf

Mota de Sá, F. (2017). Portfolio: procedures for minimizing the risk of non-structural damages. Deliverable C4. KnowRISK project (https://knowriskproject.com/wp-content/uploads/2017/05/KR_Deliverable-C4.pdf)

Musacchio, G., S. Falsaperla, S. Solarino, G.L. Piangiamore, M. Crescimbene, N.A. Pino, E. Eva, D. Reitano, F. Manzoli, M. Fabbri, M. Butturi, and M. Accardo (2018). KnowRISK on Seismic Risk Communication: the set-up of a participatory strategy. In Rupakhety R., S. Olafsson and B. Bessason (eds). Proceedings of the International Conference on Earthquake Engineering and Structural Dynamics, Geotechnical, Geological and Earthquake Engineering, Springer International Publishing AG, 47, 413-427. https://doi.org/10.1007/978-3-319-78187-7_31

Musacchio, G., E. Eva and Piangiamore, G.L. (2018). The KnowRISK Action for Schools: A case study in Italy. In Rupakhety R., S. Olafsson and B. Bessason (eds). Proceedings of the International Conference on Earthquake Engineering and Structural Dynamics, Geotechnical, Geological and Earthquake Engineering, Springer International Publishing AG, 47, 459-470. https://doi.org/10.1007/978-3-319-78187-7_34

Musacchio, G. and S. Solarino (2019). Seismic risk communication: an opportunity for prevention, Bollettino di Geofisica Teorica ed Applicata, 60, 2, 295-314. DOI 10.4430/bgta0273

O’Neill, H., M.A Ferreira, C.S. Oliveira, M. Lopes, S. Solarino, G. Musacchio, P.Candeias, M. Vicente and D.S. Silva (2018). KnowRISK Practical Guide for mitigation of seismic risk due to non-structural components. In Rupakhety R., S. Olafsson and B. Bessason (eds). Proceedings of the International Conference on Earthquake Engineering and Structural Dynamics, Geotechnical, Geological and Earthquake Engineering, Springer International Publishing AG, 47, 309-321, https://doi.org/10.1007/978-3-319-78187-7_23

Perry, C., M. Phipps and A. Hortacsu (2012). Reducing the Risks of Nonstructural Earthquake Damage. ATC and SEI Conference on Improving the Seismic Performance of Existing Buildings and Other Structures. https://doi.org/10.1061/41084(364)62.

Platt, S., G. Musacchio, M. Crescimbene, N.A. Pino, D.S. Silva, M.A. Ferreira, C.S. Oliveira and M. Lopes (2018). 
Development of a common (European) tool to assess earthquake risk communication. In: R. Rupakhety $\cdot \mathrm{S}$. Olafsson and B. Bessason, Proceedings of the International Conference on Earthquake Engineering and Structural Dynamics, Geotechnical, Geological and Earthquake Engineering, Springer International Publishing AG, 47, 493-510. https://doi.org/10.1007/978-3-319-78187-7_37

Reitano, D., S. Falsaperla, G. Musacchio and R, Merenda, (2018). Awareness on seismic risk: How can augmented reality help? In: R. Rupakhety, S. Olafsson and B. Bessason (eds.), Proceedings of the International Conference on Earthquake Engineering and Structural Dynamics, Geotechnical, Geological and Earthquake Engineering, Springer International Publishing AG, 47, 485-492. https://doi.org/10.1007/978-3-319-78187-7_36

Sankaranarayanan, R. (2007). Seismic response of acceleration-sensitive non-structural components mounted on moment-resisting frame structures. PhD thesis, University of Maryland.

Silva, D.S., M. Vicente, A. Pereira, R. Bernardo, M.A. Ferreira, M. Lopes, C.S. Oliveira and P. Henriques (2017). Risk communication - KnowRISK intervention, The Portuguese case. In: Proceedings of the International Conference on Earthquake Engineering and Structural Dynamics, 12-14 June 2017.

Silva, D.S., M. Vicente, A. Pereira, R. Bernardo, P. Candeias, M.A. Ferreira, M. Lopes, C.S. Oliveira and P. Henriques. (2018). Shaping favorable beliefs towards seismic protection through risk communication: A Pilot-Experience in Two Lisbon Schools (Portugal). In: R. Rupakhety, S. Olafsson and B. Bessason (eds.), Proceedings of the International Conference on Earthquake Engineering and Structural Dynamics, Geotechnical, Geological and Earthquake Engineering, Springer International Publishing AG, 47, 445-449. https://doi.org/10.1007/978-3319-78187-7_33

Solarino, S., G. Musacchio, M.A. Ferreira and E. Eva (2021). Playing games for risk prevention: design, implementation and testing. Annals of Geophysics, 64, (this issue), https://doi.org/10.4401/ag-8436

Spence, R., M. Lopes, P. Bisch, A. Plumier and M. Dolce (2007). Earthquake risk reduction in the European Union. Proposals for a European earthquake risk reduction programme - a discussion document. European Association for Earthquake Engineering. http://www.civil.ist.utl.pt/ mlopes/conteudos/EP/EURiskReduction.pdf

World Bank Group (2017) Non-Structural (Falling Hazards) Mitigation Manual for Schools, Ministry of Home and Cultural Affairs, Royal Government of Bhutan, (https://documents.worldbank.org/en/publication/documentsreports/documentdetail/421021468013815982/bhutan-improving-resilience-to-seismic-risk-project-environ mental-assessment)

"CORRESPONDING AUTHOR: Stefano SOLARINO, 